\title{
Bariatric surgery and cardiovascular outcome
}

\author{
Waleed Ammar ${ }^{1 *}\left(\mathbb{D}\right.$, Hossam Abdel Basset $^{2}$, Amr AL Faramawy $^{1}$, Tarek Hegazy ${ }^{3}$ and Yasser Sharaf ${ }^{1}$
}

\begin{abstract}
Background: Obesity is recognized as a classic risk factor for atherosclerosis and subsequent cardiovascular disease (CVD). Weight loss after bariatric surgery has been associated with reduced CV mortality and total mortality in obese patients. Our aim was to study the impact of bariatric surgery on CV risk profile, cardiac structure, and function postoperatively.

Results: This prospective longitudinal study included 100 morbidly obese patients at final analysis. All patients were subjected to full clinical, laboratory, and echocardiographic examination at baseline and 6 months after bariatric surgery. The mean age of study population was $37.2 \pm 10.49$ with BMI of $47 \pm 6.82$. Females represented $84 \%$. Sleeve gastrectomy and RouX-en-Y gastric bypass were performed in $79 \%$ and $21 \%$, respectively. Surgery-related mortality and morbidity were $0.94 \%$ and $4.7 \%$, respectively. After 6 months, there were significant decreases in BMl, heart rate, SBP, DBP, and Framingham risk score $(P<0.0001)$. The prevalence of risk factors decreased as follows: hypertension $24 \%$ vs. $12 \%, P=0.0005$; DM $21 \%$ vs. $11 \%, P=0.002$; dyslipidemia $32 \%$ vs. $7 \%, P<0.0001$; and metabolic syndrome $54 \%$ vs. $26 \%, P<0.0001$. Highly significant $(P<0.0001)$ decrease in fasting PG and $2 \mathrm{~h} P P-P G$, $\mathrm{HbA1c}$, ASL, ALT, fasting total cholesterol, LDL, TG, and increase in HDL were observed after bariatric surgery. There were significant shortening in QTc interval $(P=0.009)$, decrease in LV dimensions and LV mass index $(P<0.0001)$, and increase in LV EF\% $(P=0.0003)$. BMI at follow-up showed significant positive correlation with age, Framingham risk score, and preoperative BMI $(r=0.289, P=0.0036 ; r=0.37, P=0.0054$; and $r=0.31, P=0.0081$, respectively).

Conclusion: In addition to enabling patients to achieve a substantial weight loss, bariatric surgery provides a myriad of health benefits. Weight reduction was associated with a favorable improvement in cardiovascular risk profile, cardiac structure, and function.
\end{abstract}

Keywords: Obesity, Bariatric surgery, Cardiovascular, Risk profile

\section{Background}

Obesity has become a global epidemic and major problem in the twenty-first century which influences many aspects of health [1]. Obesity has a strong causal relationship with numerous serious comorbidities that impair quality of life, shorten life expectancy, and carry a major economic burden [2]. It is estimated that at least 2.8 million adults die each year due to obesity-related cardiovascular disease [3].

\footnotetext{
* Correspondence: WaleedAmmar@kasralainy.edu.eg

${ }^{1}$ Department of Cardiology, Kasr Al Aini Hospital, Faculty of Medicine, Cairo University, Cairo 11562, Egypt

Full list of author information is available at the end of the article
}

Behavioral changes and pharmacological treatment result in reduction of only 5 to $10 \%$ in body weight [4]. On the other hand, many studies have demonstrated that bariatric surgery is associated with significant and durable weight loss and improvement of obesity-related comorbidities $[5,6]$.

There are multiple options for the surgical management of morbid obesity in the appropriate candidate. The procedures can be characterized as restrictive procedures, sleeve gastrectomy (SG); mal-absorptive procedures, bilio-pancreatic diversion with duodenal switch; or combination procedures, Roux-en-Y gastric bypass (RYGB). Although these categorizations may be overly 
simplistic, the distinctions are useful. All of these operations are commonly performed using laparoscopic approaches.

Obesity, particularly severe obesity, is capable of producing hemodynamic alterations that contribute to changes in cardiac morphology which may predispose to impairment of ventricular function and heart failure. Substantial voluntary weight loss is capable of reversing many of the hemodynamic, neurohormonal, and metabolic alterations associated with obesity [7].

\section{Aim of the work}

To assess the prevalence of cardiovascular risk factors in morbidly obese patients and to study the impact of bariatric surgery on cardiovascular $(\mathrm{CV})$ risk factors, cardiac structure, and function postoperatively.

\section{Methods}

This was a prospective longitudinal study that was conducted from January 2017 to April 2018 in Maadi Military Medical Compound and cardiology department, Cairo University. One hundred patients with body mass index $(\mathrm{BMI}) \geq 35 \mathrm{~kg} / \mathrm{m}^{2}$ aged between 18 and 70 years were included. Patients with any contraindication to surgery and those who refuse to participate in this study were excluded.

All patients had a thorough medical history and clinical examination with an emphasis on cardiac risk factors. The BMI was calculated as body weight $(\mathrm{kg}) /$ the square of the height $\left(\mathrm{m}^{2}\right)$, and waist circumference was measured in inches.

- Laboratory workup included fasting lipid profile, fasting and $2 \mathrm{~h}$ post-prandial plasma glucose, HbA1c, liver enzymes (AST and ALT), serum urea, and creatinine.

- Cardiac workup included 12 lead ECG and full echocardiographic study using (vivid 7; GE Healthcare, Horten, Norway) machine with GE S3 probe. All twodimensional guided M-mode echocardiographic measurements were taken according to the American Society of Echocardiography and the European Association of Cardiovascular Imaging guidelines [8]. Left ventricular mass was measured by using Deveraux et al.'s equation, and the definition of left ventricular hypertrophy (LVH) in this study is left ventricular mass index $(\mathrm{LVMI}) \geq 110 \mathrm{~g} / \mathrm{m}^{2}$ in females and $\geq 125 \mathrm{~g} / \mathrm{m}^{2}$ in males. Left ventricular ejection fraction was measured by using the Teichholz equation, and transmitral pulsed Doppler E and A wave was used to assess the diastolic function.

\section{Cardiovascular risk factors}

Hypertension was defined as systolic BP $(\mathrm{SBP}) \geq 140$ $\mathrm{mmHg}$, and/or diastolic BP (DBP) $\geq 90 \mathrm{mmHg}$, and/or the use of anti-hypertensive medications [9].
Diabetes mellitus was defined as a hemoglobin A1c (HbA1c) $\geq 6.5 \%$, or fasting plasma glucose (FPG) $\geq 126$ $\mathrm{mg} / \mathrm{dL}$, or a 2 -h plasma glucose $\geq 200 \mathrm{mg} / \mathrm{dL}$ and/or the use of anti-diabetic agents [10].

Dyslipidemia was considered when low-density lipoprotein (LDL) cholesterol was $\geq 130 \mathrm{mg} / \mathrm{dL}$, or highdensity lipoprotein (HDL) cholesterol $\leq 50 \mathrm{mg} / \mathrm{dL}$ in women and $\leq 40 \mathrm{mg} / \mathrm{dL}$ in men, increased triglycerides (TGs) $\geq 150 \mathrm{mg} / \mathrm{dL}$, or if the patient is currently receiving a lipid lowering agent [11].

Metabolic syndrome, according to the American Heart Association (AHA) and the National Heart, Lung, and Blood Institute (NHLBI) definition, is present if $\geq 3$ of the following 5 criteria are met: waist circumference $\geq$ 40 in. (men) or $35 \mathrm{in}$. (women), blood pressure $\geq 130 / 85$ $\mathrm{mmHg}$, fasting $\mathrm{TG} \geq 150 \mathrm{mg} / \mathrm{dL}$, fasting HDL cholesterol $<40 \mathrm{mg} / \mathrm{dL}$ (men) or $50 \mathrm{mg} / \mathrm{dL}$ (women), and FPG $\geq 100 \mathrm{mg} / \mathrm{dL}$ [12].

Framingham risk score is a gender-specific algorithm used to estimate the 10-year cardiovascular risk of an individual [13].

Estimated vascular age is the chronological age of an individual adjusted by their level of atherosclerosis. It was calculated according to the definition of D'Agostino et al. in the tables from the Framingham Heart Study [13].

\section{Follow-up}

Patients were followed up for 6 months after surgery at which they were subjected to full clinical evaluation, laboratory workup, electrocardiogram, and full echocardiographic study.

\section{Ethical approval}

The study was conducted in accordance with the Declaration of Helsinki and was approved by the Research Ethics Committee of the Faculty of Medicine (reference number I-150314). All study participants provided informed written consent.

\section{Statistical analysis}

Data entry, processing, and statistical analysis were carried out using MedCalc ver. 18.2.1 (MedCalc, Ostend, Belgium).

\section{Descriptive statistics}

Mean, standard deviation ( \pm SD), and range were used for parametric numerical data, while median and interquartile range (IQR) for non-parametric numerical data. Frequency and percentage was used for non-numerical data.

\section{Analytical statistics}

Mann-Whitney's test ( $U$ test) was used to assess the statistical significance of the difference of a non- 
parametric variable between two study groups, Wilcoxon's test for the difference of a non-parametric variable between two (paired) study group means, and repeated measures and factorial ANOVA tests for the difference between more than two (paired) study group means, with the ability to insert grouping factors, which was used to generate clustered multiple variable graphs. Chisquare test was used to examine the relationship between two qualitative variables. Correlation analysis (using Spearman's method) was used to assess the strength of association between two quantitative variables. The correlation coefficient denoted symbolically as $r$ defines the strength and direction of the linear relationship between two variables. Multiple linear regression was used to test and estimate the dependence of a quantitative variable based on its relationship with a set of independent variables, and logistic regression for the prediction of the presence or absence of an outcome based on a set of independent variables. It is similar to a linear regression model but is suited when the dependent variable is qualitative (categorical). $P$ value $<$ $0.05(5 \%)$ was considered to be statistically significant, and $P<0.01$ highly significant.

\section{Results}

One hundred and six patients fulfilled the inclusion criteria and were initially recruited in the study, one of them died postoperatively, and five patients did not complete follow-up workup. One hundred patients completed the follow-up resulting in a follow-up rate of $94 \%$ and were included in the final analysis. The mean age of study population was $37.2 \pm 10.49$ with BMI of $47 \pm$ 6.82. Females represented $84 \%$ and males $16 \%$.

\section{Operative data}

\section{Type of surgery}

Among the 100 patients who completed the follow-up analysis, sleeve gastrectomy was done in 79 patients (79\%) whereas gastric bypass was done in 21 patients (21\%).

\section{Adverse surgical outcomes}

One patient developed fatal pulmonary embolism 1 day after gastric bypass (GB) surgery. Three patients in the GB group developed anastomotic site leakage 2-4 days of the procedure that was managed surgically with a smooth course thereafter. Two patients in the GB group developed intestinal adhesions 3-4 months following surgery and were managed surgically.

\section{Impact of bariatric surgery on cardiovascular risk profile} The impact of the bariatric surgery on BMI, blood pressure, DM, dyslipidemia, and, consequently, metabolic syndrome, Framingham risk score, and estimated vascular age after 6 months of surgery is clearly shown in Table 1.

As shown in Table 2, 6 months after the bariatric surgery, there was a considerable improvement of all lipid sub-fractions and significant reduction in FPG, $2 \mathrm{~h}$ PPPG, HbA1c, and liver enzymes $(P<0.0001)$.

\section{Impact of bariatric surgery on electrocardiographic and echocardiographic measurements}

It is notable in Table 3 that weight loss with bariatric surgery resulted in significant reduction in resting heart rate and shortening in corrected QT interval as a marker of ventricular repolarization.

Echocardiographic findings at 6 months follow-up revealed significant reduction in LV dimensions and LV mass index $(P<0.0001)$. In Table 4 , it is notable that there was a significant increase in LV EF\% $(P=0.0003)$ and increase in $\mathrm{E} / \mathrm{A}$ ratio $(P<0.0001)$.

\section{Correlation studies}

Using Spearman's correlation coefficient, there has been a statistically significant positive correlation between BMI at 6 months follow-up and clinical variables including age, heart rate, vascular age, Framingham score, and preoperative $\mathrm{BMI}(r=0.289, P=0.0036 ; r=0.24, P=$ $0.015 ; r=0.79, P<0.0001 ; r=0.37, P=0.0054$; and $r=$ $0.31, P=0.0081$, respectively). Such correlations are shown in Figs. 1, 2, 3, and 4.

Spearman's correlation analysis showed that preoperative echocardiographic findings, LA, AO, LVESD, IVSD, PWD, LV mass index, and A wave, had a highly significant positive correlation with 6 months postoperative BMI, whereas $\mathrm{E}$ wave and E/A ratio had a highly significant negative correlation with 6 months postoperative BMI (Table 5). Finally, multiple regression model using forward method revealed significant positive correlation (age and preoperative $\mathrm{BMI}$ ) and significant negative correlation (preoperative EF) with postoperative BMI (Table 6).

\section{Discussion}

This was a prospective longitudinal trial; the mean age of study population was $37.2 \pm 10.49$ years. The majority $(84 \%)$ of patients were females. These demographic characteristics were consistent with previous studies. In a meta-analysis involving 134 studies and an aggregate of 22,094 patients, $73 \%$ of them were females, with an average age of 39 years [14]. As in the current study, the population undergoing bariatric surgery is predominantly female in the fourth decade of life, probably when the metabolic and hemodynamic complications resulting from excess body weight appear from the clinical point of view. It is worth mentioning that, in our study, age was among the most important variables affecting BMI 
Table 1 Clinical characteristics preoperative and 6 months after bariatric surgery

\begin{tabular}{|c|c|c|c|c|}
\hline Variables & & $\begin{array}{l}\text { Preoperative measurements, } \\
\text { median (IQR) }\end{array}$ & $\begin{array}{l}6 \text { months FU measurements, } \\
\text { median (IQR) }\end{array}$ & $P$ value ${ }^{\mathrm{a}}$ \\
\hline BMI & & $45(43.2-49.3)$ & $32.8(31.1-35.7)$ & $<0.0001^{* *}$ \\
\hline Systolic BP & & $125(120-132.5)$ & $120(115-130)$ & $<0.0001^{* *}$ \\
\hline Diastolic BP & & $80(70-85)$ & $78(70-80)$ & $=0.0002^{* *}$ \\
\hline Estimated vascular age & & $51(36-76)$ & $42(34-61)$ & $<0.0001^{* *}$ \\
\hline Framingham risk score & & $5.3(2-13.3)$ & $2.8(1.6-7.3)$ & $<0.0001^{* *}$ \\
\hline Variables & & Preoperative measurements & 6 months FU measurements & $P$ value $^{\mathrm{b}}$ \\
\hline Hypertension & & $24(24 \%)$ & $12(12 \%)$ & $=0.0005^{* *}$ \\
\hline Diabetes mellitus & & $21(21 \%)$ & $11(11 \%)$ & $=0.002^{* *}$ \\
\hline Dyslipidemia & & $32(32 \%)$ & $7(7 \%)$ & $<0.0001^{* *}$ \\
\hline Metabolic syndrome & & $54(54 \%)$ & $26(26 \%)$ & $<0.0001^{* *}$ \\
\hline \multirow[t]{3}{*}{ Risk category (Framingham risk score) } & Low & $45(61.6 \%)$ & $57(78.1 \%)$ & $<0.0001^{* *}$ \\
\hline & Moderate & $7(9.6 \%)$ & $4(5.5 \%)$ & \\
\hline & High & $21(28.8 \%)$ & $12(16.4 \%)$ & \\
\hline
\end{tabular}

$B M I$ Body Mass index, BP Blood pressure, IQR Interquartile range

aUsing Wilcoxon's test

${ }^{b}$ Using chi-square test

at follow-up that signify more expected weight loss when having surgery at younger age.

In our series, surgery-related mortality and morbidity were $0.9 \%$ and $4.7 \%$, respectively. This remarkable accomplishment is primarily due to the introduction of laparoscopic techniques and a long-standing emphasis on safety and quality improvement [15]. In the American College of Surgeons Bariatric Surgery Network database, mortality 30 days after sleeve gastrectomy was $0.11 \%$ and Roux-en-Y gastric bypass $0.14 \%$. The 30 -day morbidity rate was $5.6 \%$ for sleeve gastrectomy and 5.9\% for Rouxen-Y gastric bypass [16].
Regarding cardiovascular risk profile, the prevalence of hypertension was $21 \%$ with mean systolic and diastolic $\mathrm{BP}$ of $127 \pm 13.5$ and $80 \pm 9.5 \mathrm{mmHg}$ respectively. Dyslipidemia was evident in $32 \%$ of our patients, and the prevalence of DM was $24 \%$ with mean FBS and HbA1c of $99.8 \pm 36.8 \mathrm{mg} / \mathrm{dL}$ and $5.6 \pm 1.1 \%$, respectively.

The prevalence of metabolic syndrome at baseline was $54 \%$. This prevalence was low compared to other studies $[17,18]$, and this may be explained, at least in part, by the relatively low prevalence of dyslipidemia and hypertension in our study cohort. According to the Framingham risk score to estimate the risk of fatal or nonfatal

Table 2 Laboratory workup preoperative and 6 months after bariatric surgery

\begin{tabular}{llll}
\hline Variables & Preoperative measurements, median (IQR) & $\mathbf{6}$ months FU measurements, median (IQR) & $\boldsymbol{P}$ value \\
\hline Total cholesterol $(\mathrm{mg} / \mathrm{dL})$ & $195.5(168-240)$ & $170(150-200)$ & $<0.0001^{* *}$ \\
TGs $(\mathrm{mg} / \mathrm{dL})$ & $102(80-156.5)$ & $90.5(73.5-120)$ & $<0.0001^{* *}$ \\
$\mathrm{LDL}(\mathrm{mg} / \mathrm{dL})$ & $100(86-120)$ & $94(82-100)$ & $<0.0001^{* *}$ \\
HDL $(\mathrm{mg} / \mathrm{dL})$ & $51(47.5-57)$ & $54(50.5-59)$ & $<0.0001^{* *}$ \\
FPG $(\mathrm{mg} / \mathrm{dL})$ & $84(75-111.5)$ & $78(72.5-100)$ & $<0.0001^{* *}$ \\
PP-PG $(\mathrm{mg} / \mathrm{dL})$ & $115.5(103-142)$ & $5(10(102-126)$ & $<0.0001^{* *}$ \\
HbA1C $(\mathrm{mg} / \mathrm{dL})$ & $5.1(4.9-5.9)$ & $25.5(20.5-36.5)$ & $<0.0001^{* *}$ \\
ALT $(\mathrm{U} / \mathrm{L})$ & $29(22.5-44.5)$ & $25(17-32.5)$ & $<0.0001^{* *}$ \\
AST $(\mathrm{U} / \mathrm{L})$ & $29(20.5-43)$ & $0.7(0.6-0.7)$ & $<0.0001^{* *}$ \\
Creatinine $(\mathrm{mg} / \mathrm{dL})$ & $0.7(0.6-0.8)$ & $20(17-27)$ & $<0.146$ \\
Urea $(\mathrm{mg} / \mathrm{dL})$ & $24(19-34)$ & $<0.0001^{* *}$ \\
\hline
\end{tabular}

ALT Alanine aminotransferase, AST Aspartate aminotransferase, FPG Fasting plasma glucose, HbA1c Glycosylated hemoglobin, HDL High-density lipoprotein, IQR interquartile range, $L D L$ Low-density lipoprotein, $P$ P-PG Post-prandial plasma glucose, TGs Triglycerides

a Using Wilcoxon's test 
Table 3 Electrocardiographic findings preoperative and 6 months after bariatric surgery

\begin{tabular}{llll}
\hline Variables & Preoperative measurement, median (IQR) & $\mathbf{6}$ months FU measurements, median (IQR) & $\boldsymbol{P}$ value ${ }^{\mathbf{a}}$ \\
\hline Heart rate $(\mathrm{bpm})$ & $82(75-92)$ & $76(71-82)$ & $<0.0001^{* *}$ \\
PR interval (msec) & $160(140-160)$ & $160(150-162)$ & $=0.354$ \\
QRS complex width (msec) & $80(80-100)$ & $80(80-100)$ & $=1.000$ \\
QTc interval (msec) & $432(416-447)$ & $423(409-447)$ & $=0.0094^{* *}$ \\
\hline
\end{tabular}

bpm Beats per minute, IQR Interquartile range, msec Milliseconds

asing Wilcoxon's test

coronary events in 10 years, risk categories in the current study were low (61.6\%), intermediate (9.6\%), and high $(28.8 \%)$. Consistent with our results, in baseline analysis of the recent Traditional Brazilian Diet Trial including 150 adult patients, $55.3 \%$ of the study participants were classified as low risk, $4.7 \%$ as intermediate risk, and $40.0 \%$ as high 10 -year CHD risk [19].

Bariatric surgery was associated with significant decrease in BMI after 6 months (45 (43.2-49.3) vs. 32.8 (31.1-35.7) with $P$ value $<0.0001)$. This was in agreement with previous studies. De La Cruz-Muñoz et al. [20] studied the effectiveness of bariatric surgery in 71 patients. After 1 year, BMI was reduced from 49.7 to $39.2 \mathrm{~kg} / \mathrm{m}^{2}$ among males and from 45.1 to $34.4 \mathrm{~kg} / \mathrm{m}^{2}$ among females. In another study, Hady et al. [21] studied the impact of laparoscopic sleeve gastrectomy in 100 obese patients with 6 months follow-up period and reported significant reduction of BMI from $52.15 \pm 8.5$ to $37.98 \pm 4.97 \mathrm{~kg} / \mathrm{m}^{2}$.

Bariatric surgery was associated with significant improvement in various cardiovascular risk factors after 6 months in our study. The prevalence of hypertension decreased from 21 to $11 \%$ (47\% remission) with highly significant decrease in systolic blood pressure $(P<0.0001)$ and diastolic blood pressure $(P=0.0002)$. In a study by Zhang et al. [22] with a total of 558 patients who underwent either LSG (200) or RYGB (358) for morbid obesity, the prevalence of hypertension was $52 \%$ at baseline, and after 6 months follow-up, there was $40 \%$ remission of hypertension. Additionally, in the systematic review of Heneghan et al., the prevalence of hypertension was $49 \%$ with $68 \%$ resolution or reduction in hypertension after a mean follow-up period of 34 months after bariatric surgery [23].

The prevalence of DM decreased from 24 to $12 \%$ (50\% remission) and additional $16.6 \%$ reduction in needed medications. At Cleveland Clinic, 150 obese patients with T2DM were randomized to conventional medical therapy, RYGB, or SG. After 12 months, the primary endpoint which was the proportion of patients achieving HbA1c of $6.0 \%$ or less after treatment was achieved in $42 \%$ of the RYGB arm, $37 \%$ of the LSG arm, and $12 \%$ of the conventional medical therapy arm [24]. It is worth mentioning that the 2nd Diabetes Surgery Summit International Consensus Conference published recommendations that bariatric surgery should be considered as a treatment option for patients with T2D [25].

The prevalence of dyslipidemia decreased from 32 to $7 \%$ with resolution of dyslipidemia in $78 \%$ of our

Table 4 Echocardiographic measurements preoperative and 6 months after bariatric surgery

\begin{tabular}{llll}
\hline Variables & Preoperative measurements, median (IQR) & $\mathbf{6}$ months FU measurements, median (IQR) & $\boldsymbol{P}$ value ${ }^{\mathbf{a}}$ \\
\hline LA $(\mathrm{cm})$ & $3.2(2.9-3.7)$ & $3.2(2.9-3.7)$ & $=1.000$ \\
AO $(\mathrm{cm})$ & $3.05(2.8-3.45)$ & $3(2.8-3.45)$ & $<0.273$ \\
LVEDD $(\mathrm{cm})$ & $4.95(4.6-5.4)$ & $4.9(4.5-5.3)$ & $<0.0001^{* *}$ \\
LVESD $(\mathrm{cm})$ & $3.1(2.7-3.5)$ & $3(2.7-3.4)$ & $<0.0001^{* *}$ \\
IVSD $(\mathrm{cm})$ & $1(0.8-1.2)$ & $1(0.8-1)$ & $=0.735$ \\
PWD $(\mathrm{cm})$ & $1(0.8-1.1)$ & $0.99(0.8-1.1)$ & $=0.441$ \\
FS $(\%)$ & $36(33-40)$ & $37.5(34-40)$ & $<0.0001^{* *}$ \\
EF $(\%)$ & $65(62-69)$ & $67(63-69)$ & $=0.0003^{* *}$ \\
LVMI $\left(\mathrm{g} / \mathrm{m}^{2}\right)$ & $47.7(32.2-59.2)$ & $40.5(29.4-51.1)$ & $<0.0001^{* *}$ \\
E wave $(\mathrm{m} / \mathrm{s})$ & $0.8(0.7-0.9)$ & $0.8(0.7-0.92)$ & $=0.365$ \\
A wave $(\mathrm{m} / \mathrm{s})$ & $0.5(0.5-0.65)$ & $0.5(0.5-0.6)$ & $=0.401$ \\
E/A ratio & $1.5(1.2-1.8)$ & $1.6(1.5-1.8)$ & $<0.0001^{* *}$ \\
\hline
\end{tabular}

$A O$ Aortic root, EF ejection fraction, FS Fractional shortening, IQR Interquartile range, IVSD Interventricular septal dimension, LVEDD Left ventricular end diastolic dimension, LVESD Left ventricular end systolic dimension, LVMI Left ventricular mass index, PWD Posterior wall dimension

a Using Wilcoxon's test 


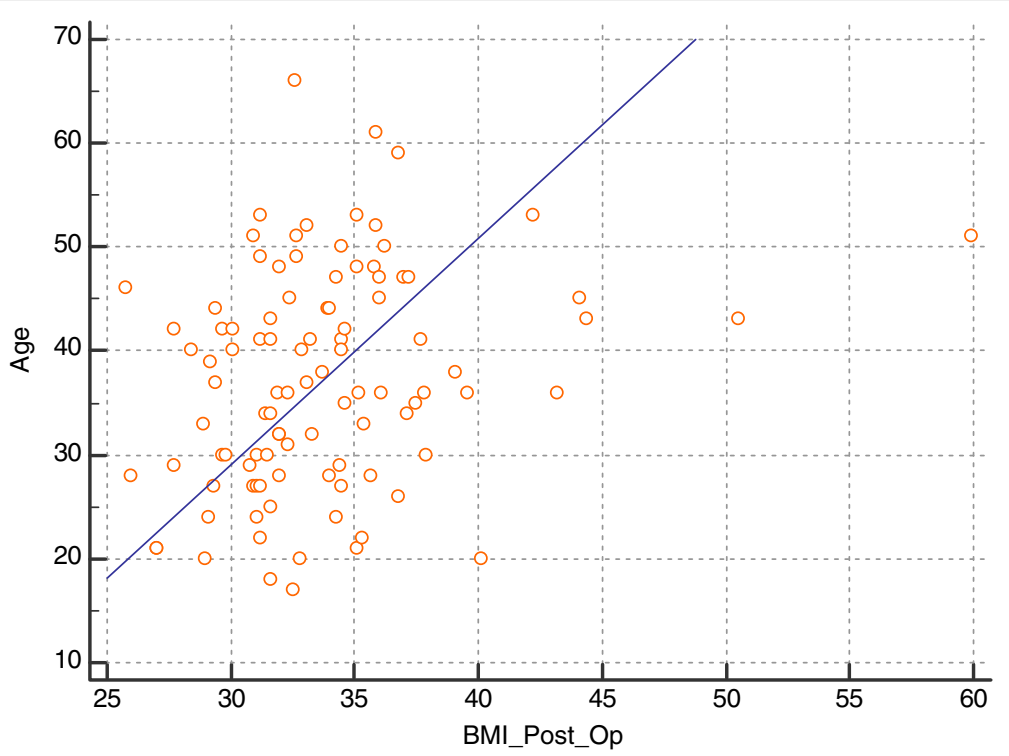

Fig. 1 Correlation between postoperative BMI and age

patients. Considerable improvement of all lipid subfractions was observed during follow-up in our study. This comes in concordance with Singhal et al. [26] who studied the effect of LSG on lipid profile of 50 obese patients. LSG resolved or improved lipid profile in a majority of patients during initial first 6 months after surgery. In another study, Strain et al. [27] studied 82 patients ( $67 \%$ female, age $46.4 \pm 13.9$ ) subjected to bariatric surgery. At 1 year, there was a significant reduction in triglycerides $(P=0.004)$ and significant increase in HDL $(P$ $=0.025)$, while total cholesterol and LDL cholesterol showed no significant difference at follow-up. Furthermore, the systematic review of Heneghan et al. [23] came up with concordant results showing $71 \%$ resolution or reduction in dyslipidemia.

The prevalence of metabolic syndrome decreased from 54 to $26 \%$ at 6 months after bariatric surgery with $52 \%$ reduction in its prevalence. Batsis et al. [18] performed a population-based, retrospective study, in which bariatric surgery resulted in $67 \%$ reduction in the prevalence of metabolic syndrome. The number of patients with metabolic syndrome decreased from $156(87 \%)$ to $53(29 \%)$

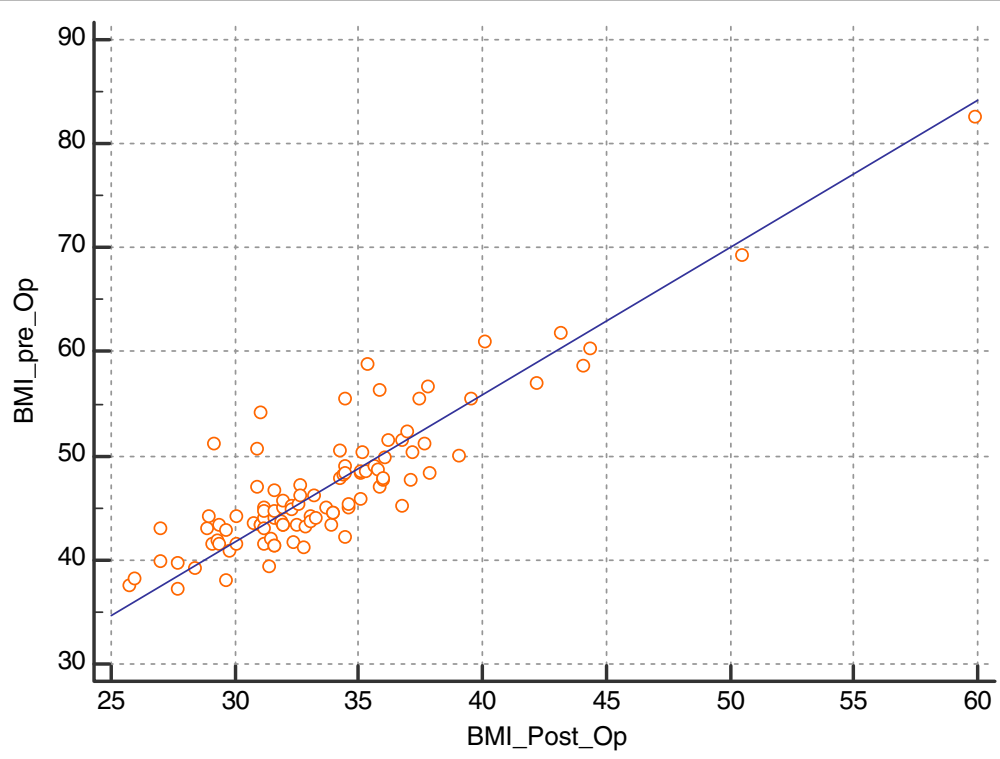

Fig. 2 Correlation between postoperative BMI and preoperative BMI 


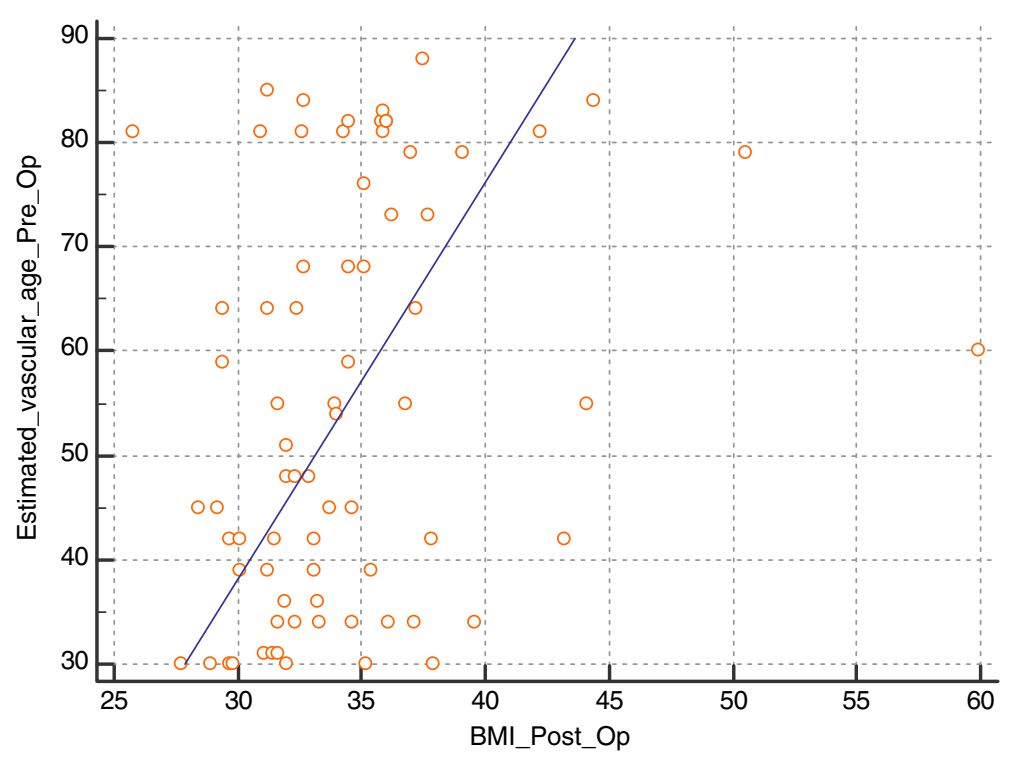

Fig. 3 Correlation between postoperative BMI and preoperative estimated vascular age

after a mean follow-up of 3.4 years. Silva et al. [17] performed a prospective observational study composed of 96 patients with obesity, among which 86 were women, aged between 18 and 58 years old. At the end of 6 months, bariatric surgery resulted in $80 \%$ reduction in the prevalence of metabolic syndrome $(69 \%$ vs. $14 \%, P<$ 0.0001).

At 6 months follow-up, there was a significant decrease in the estimated risk of fatal or nonfatal coronary events in 10 years according to the Framingham risk score $(P<0.0001)$ and estimated vascular age $(P<$ $0.0001)$. In a recent study conducted by Blanco et al.
[28] involving 360 patients with bariatric surgery, LSG was the most prevalent surgery (63\%), followed by RYGB (20.6\%), and reported significant reduction of both atherosclerotic cardiovascular disease and Framingham risk scores at 12 months. In another study, Wei et al. [29] recently investigated the benefit of CVD risk reduction after metabolic surgery in 392 obese patients with type 2 DM who had undergone LSG (87) or RYGB (305). The estimated 10-year coronary heart disease risk was reduced from 8.8 to $4.6 \%(P<0.001)$. It is worth mentioning that our study further demonstrated statistically significant positive correlations between Framingham

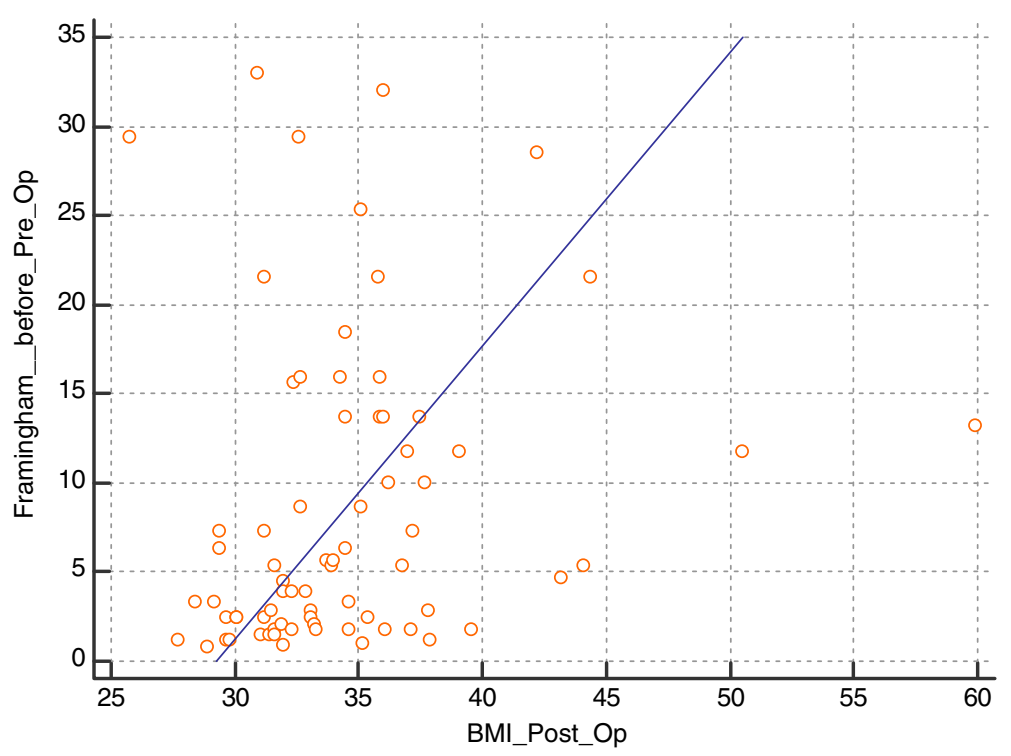

Fig 4 Correlation between postoperative BMI and preoperative Framingham score 
Table 5 Correlations of echocardiographic data and postoperative BMI

\begin{tabular}{|c|c|c|}
\hline & $r$ & $P$ value ${ }^{a}$ \\
\hline$\overline{\mathrm{LA}(\mathrm{cm})}$ & 0.223 & $=0.025^{*}$ \\
\hline $\mathrm{AO}(\mathrm{cm})$ & 0.288 & $=0.0037^{* *}$ \\
\hline LVEDD $(\mathrm{cm})$ & 0.183 & $=0.0683$ \\
\hline LVESD (cm) & 0.213 & $=0.033^{*}$ \\
\hline IVSD (cm) & 0.450 & $<0.0001^{* *}$ \\
\hline PWD (cm) & 0.273 & $=0.0061^{* *}$ \\
\hline FS (\%) & -0.170 & $=0.0917$ \\
\hline EF (\%) & -0.172 & $=0.0864$ \\
\hline LV MI (g/m²) & 0.355 & $=0.0003^{* *}$ \\
\hline E wave $(\mathrm{m} / \mathrm{s})$ & -0.316 & $=0.0014^{* *}$ \\
\hline A wave $(\mathrm{m} / \mathrm{s})$ & 0.258 & $=0.0097^{* *}$ \\
\hline E/A ratio & -0.297 & $=0.0027^{* *}$ \\
\hline
\end{tabular}

$A O$ Aortic root, EF Ejection fraction, FS fractional shortening, IVSD Interventricular septal dimension, LVEDD Left ventricular end diastolic dimension, LVESD Left ventricular end systolic dimension, LVMI Left ventricular mass index, PWD Posterior wall dimension

a Using Spearman's correlation coefficient

risk score, estimated vascular age, and postoperative 6month BMI using Spearman's correlation coefficient.

Electrocardiographic findings at 6 months follow-up revealed significant reduction in resting heart rate and shortening in QTc interval $(P<0.0001$ and 0.009 , respectively). Owan et al. [30] in the Utah Obesity Study included 423 severely obese patients undergoing bariatric surgery. At a 2-year follow-up, there was a large reduction in heart rate from $74 \pm 12$ to $60 \pm 10$. Omran et al. [31] performed a systematic review and meta-analysis of the effects of obesity and weight loss on the corrected QT interval. Weight loss was associated with a significant decrease in QTc (mean difference - $25.77 \mathrm{~ms}, 95 \% \mathrm{CI}-28.33-23.21$ ). In another study, Mukerji et al. [32] investigated the effect of weight loss on ventricular repolarization in 39 normotensive morbidly obese patients. Again, weight loss was associated with significant reductions in mean QTc (from $428.7 \pm 18.5$ to $410.5 \pm 11.9 \mathrm{~ms}, P<0.0001)$. LV hypertrophy was a key determinant of QTc interval, and regression of LV hypertrophy related to weight loss was associated with shortening of QTc interval.

Table 6 Multiple regression model for the factors affecting postoperative BMI

\begin{tabular}{llll}
\hline Predictor factor & $\boldsymbol{\beta}$ & SE & $\boldsymbol{P}$ value \\
\hline Constant & -5.7961 & & \\
Age & 0.06057 & 0.02102 & $0.0049^{* *}$ \\
BMI (pre-op) & 0.6408 & 0.03352 & $<0.0001^{* *}$ \\
EF\% (pre-op) & -0.1102 & 0.04636 & $0.019^{*}$ \\
\hline
\end{tabular}

$B M I$ Body mass index, EF Ejection fraction, $\beta$ Regression coefficient, $S E$ Standard error; using forward method
Bariatric surgery has been noted to induce changes in heart geometry and function, both systolic and diastolic. In our study, echocardiographic findings at 6 months follow-up revealed significant reduction in LV dimensions and LV mass index $(P<0.0001)$, increase in LV $\mathrm{EF} \%(P=0.0003)$, and increase in $\mathrm{E} / \mathrm{A}$ ratio $(P<0.0001)$. Mauricio et al. [33] assessed the effect of BS in 41 patients, and there was a significant reduction in LVMI $(101.3 \pm 38.34$ vs. $86.70 \pm 26.65, P=0.005)$ and increase in LV shortening fraction $(31.05 \pm 8.82 \%$ vs. $36.34 \pm$ $8.21 \%, P=0.007)$. Aggarwal et al. [34], in their systematic review and meta-analysis of the effect of bariatric surgery on cardiac structure and function, reported significant decrease of both left ventricular mass (mean decrease of $30 \mathrm{~g}$ ) and mass index (mean decrease of $11 \%$ ) in addition to significant decrease in LV end diastolic and systolic volumes and significant improvement in ejection fraction. Improvement of diastolic function postsurgical weight loss was also demonstrated by some other studies $[35,36]$. It has been postulated that perivascular and interstitial LV fibrosis may contribute to LV diastolic dysfunction in obesity [37]. Our study sheds light on another potential and clinically relevant correlations; postoperative BMI showed significant correlation with LV mass index using Spearman's correlation and with $\mathrm{EF} \%$ using multiple regression model.

\section{Conclusion}

Accumulating evidence supports our findings of significant cardiovascular risk reduction after bariatric surgery. Bariatric surgeries are reasonably safe procedures, and in addition to enabling patients to achieve a substantial weight loss, bariatric surgeries provide a myriad of health benefits. Major cardiovascular risk factors namely hypertension, diabetes mellitus, and dyslipidemia were reduced by $47 \%, 50 \%$, and $78 \%$, respectively. Additionally, the prevalence of metabolic syndrome, severity of Framingham risk score, and estimated vascular age were significantly improved after surgery. It should also be emphasized that a significant decrease in LV dimensions and LV mass index together with significant increase in LV ejection fraction was achieved at follow-up.

\section{Limitations}

The findings from our study have to be considered in the context of some study limitations as well. First, there is a relatively short-term follow-up period after surgery. Second, personal differences in behavior, lifestyle, and treatment adherence postoperatively may have contributed to some extent in the observed outcome. Third, there is a lack of a control group. However, methodological methods are comparable to other recently published studies. 


\section{Abbreviations}

ALT: Alanine aminotransferase; AST: Aspartate aminotransferase; BMI: Body mass index; BS: Bariatric surgery; CHD: Coronary heart disease; CVD: Cardiovascular disease; DM: Diabetes mellitus; EF: Ejection fraction; FPG: Fasting plasma glucose; FS: Fractional shortening; HDL: High-density lipoprotein; LA: Left atrium; LDL: Low-density lipoprotein; LVEDD : Left ventricular end diastolic dimension; LVESD: Left ventricular end systolic dimension; PP-PG: Post-prandial plasma glucose; PWD: Posterior wall dimension; RYGB: Roux-en-Y gastric bypass; SG: Sleeve gastrectomy; IVSD: Interventricular septal dimension; TGs: Triglycerides; TTE: Transthoracic echocardiography

\section{Acknowledgements}

The authors gratefully acknowledge the valuable contribution of general surgery department members, Maadi Military Medical Compound, for their valuable contribution in the recruitment and management of patients in this study.

\section{Authors' contributions}

YS, WA, and AF were the principal investigators and carried out the study design. WA and AF were involved in the supervision, auditing, and reviewing of cases. HAB was responsible for the recruitment and assessment of patients, database entry, collection of laboratory workup, performance of echocardiographic studies, and follow-up of patients. WA wrote the manuscript. All authors have read and approved the manuscript.

\section{Funding}

This research did not receive any specific grant from funding agencies in the public, commercial, or not-for-profit sectors.

\section{Availability of data and materials}

The datasets used and/or analyzed during the current study are available from the corresponding author on reasonable request.

\section{Ethics approval and consent to participate}

This research involved human subjects and was performed in accordance with the Declaration of Helsinki and approved by Cairo University-Faculty of Medicine Ethical Committee. The Committee provided a reference number (I-150314)

A written informed consent was obtained from all patients.

\section{Consent for publication}

Not applicable.

\section{Competing interests}

The authors declare that they have no competing interests.

\section{Author details}

'Department of Cardiology, Kasr Al Aini Hospital, Faculty of Medicine, Cairo University, Cairo 11562, Egypt. ${ }^{2}$ Department of Cardiology, Military Medical Academy, Cairo, Egypt. ${ }^{3}$ Department of General Surgery, Faculty of Medicine, Cairo University, Cairo 11562, Egypt.

Received: 6 June 2020 Accepted: 4 September 2020

Published online: 02 October 2020

\section{References}

1. World Health Organization. Obesity. Preventing and managing the global epidemic. World Health Organ Tech Rep Ser. 2000; No.894.

2. English WJ, Williams DB (2018) Metabolic and bariatric surgery: an effective treatment option for obesity and cardiovascular disease. Prog Cardiovasc Dis 61(2):253-269. https://doi.org/10.1016/j.pcad.2018.06.003

3. Ford ES, Giles WH, Dietz WH (2002) Prevalence of the metabolic syndrome among US adults: findings from the third National Health and Nutrition Examination Survey. JAMA 287:356-359. https://doi.org/10.1001/jama.287.3.356

4. Adams TD, Davidson LE, Litwin SE et al (2012) Health benefits of gastric bypass surgery after 6 years. JAMA 308(11):1122-1131. https://doi.org/10. 1001/2012.jama.11164

5. Flum DR, Belle SH, King WC, Wahed AS et al (2009) Perioperative safety in the longitudinal assessment of bariatric surgery. N Engl J Med 361:445-454. https://doi.org/10.1056/NEJMoa0901836
6. Karlsson J, Taft C, Ryden A, Sjostrom L, Sullivan M (2007) Ten-year trends in health-related quality of life after surgical and conventional treatment for severe obesity: the SOS intervention study. Int J Obes 31:1248-1261. https:// doi.org/10.1038/sj.ijo.0803573

7. Alpert MA, Karthikeyan K, Abdullah O, Ghadban R (2018) Obesity and cardiac remodeling in adults: mechanisms and clinical implications. Prog Cardiovasc Dis 61(2):114-123. https://doi.org/10.1016/j.pcad.2018.07.012

8. Lang RM, Badano LP, Mor-Avi V et al (2015) Recommendations for cardiac chamber quantification by echocardiography in adults: an update from the American Society of Echocardiography and the European Association of Cardiovascular Imaging. Eur Heart J Cardiovasc Imaging 16(3):233-270. https://doi.org/10.1093/ehjci/jev014

9. Williams B, Mancia G, Spiering W et al (2018) ESC Scientific Document Group, 2018 ESC/ESH guidelines for the management of arterial hypertension: the Task Force for the management of arterial hypertension of the European Society of Cardiology (ESC) and the European Society of Hypertension (ESH). Eur Heart J 39(1):3021-3104

10. American Dietetic Association. Classification and diagnosis of diabetes: standards of medical care in diabetes 2018. Diabetes Care 2018; 41:S13-S27. http://https://doi.org/10.2337/dc18-S002.

11. Catapano AL, Reiner Ž, De Backer $G$ et al (2011) ESC/EAS guidelines for the management of dyslipidaemias: the Task Force for the management of dyslipidaemias of the European Society of Cardiology (ESC) and the European Atherosclerosis Society (EAS). Atherosclerosis 217:1-44

12. Grundy SM, Cleeman JI, Daniels SR et al (2005) Diagnosis and management of the metabolic syndrome: an American Heart Association/National Heart, Lung, and Blood Institute Scientific statement. Circulation 112:2735-2752

13. D'Agostino RB Sr, Vasan RS, Pencina MJ et al (2008) General cardiovascular risk profile for use in primary care: the Framingham Heart Study. Circulation 117:743-753

14. Buchwald $H$, Avidor $Y$, Braunwald E et al (2004) Bariatric surgery: a systematic review and meta-analysis. JAMA 292:1724-1737

15. Chaar ME, Lundberg P, Stoltzfus J (2018) Thirty-day outcomes of sleeve gastrectomy versus Roux-en-Y gastric bypass: first report based on Metabolic and Bariatric Surgery Accreditation and Quality Improvement Program database. Surg Obes Relat Dis 14:545-551

16. Lee GK, Cha YM (2016) Cardiovascular benefits of bariatric surgery. Trends Cardiovasc Med 26:280-289

17. Silva MA, Rivera IR, Barbosa EM, Crispim MA et al (2013) Frequency of cardiovascular risk factors before and 6 and 12 months after bariatric surgery. Rev Assoc Med Bras 59(4):381-386

18. Batsis JA, Romero-Corral A, Collazo-Clavell M et al (2008) The effect of bariatric surgery on the metabolic syndrome: a population-based, long-term controlled study. Mayo Clin Proc 83(8):897-907

19. Santos ASAC, Rodrigues APS, Rosa LPS et al (2020) Cardiometabolic risk factors and Framingham Risk Score in severely obese patients: baseline data from DieTBra trial. Nutr Metabol Cardiovasc Dis 3:474-482

20. De La Cruz-Muñoz N, Lopez-Mitnik G, Arheart KL et al (2013) Effectiveness of bariatric surgery in reducing weight and body mass index among Hispanic adolescents. Obes Surg 23(2):150-156

21. Hady HR, Dadan J, Gołaszewski P, Safiejko K (2012) Impact of laparoscopic sleeve gastrectomy on body mass index, ghrelin, insulin and lipid levels in 100 obese patients. Wideochir Inne Tech Maloinwazyjne 7(4):251-259. https://doi.org/10.5114/wiitm.2011.28979

22. Zhang N, Maffei A, Cerabona T et al (2013) Reduction in obesity-related comorbidities: is gastric bypass better than sleeve gastrectomy? Surg Endosc 27(4):1273-1280

23. Heneghan HM, Meron-Eldar S, Brethauer SA et al (2011) Effect of bariatric surgery on cardiovascular risk profile. Am J Cardiol 108(10):1499-1507

24. Schauer PR, Kashyap SR, Wolski K et al (2012) Bariatric surgery versus intensive medical therapy in obese patients with diabetes. N Engl J Med 366:1567-1576. https://doi.org/10.1056/NEJMoa1200225

25. Rubino F, Nathan DM, Eckel RH et al (2016) Metabolic surgery in the treatment algorithm for type 2 diabetes: a joint statement by International Diabetes Organizations. Surg Obes Relat Dis 12(6):1144-1162

26. Singhal S, Agarwal D, Kanojiya R et al (2016) Effect of laparoscopic sleeve gastrectomy on lipid profile of obese patients in complete nine month follow up. Int Surg J 3(1):42-46

27. Strain GW, Saif T, Ebel F et al (2015) Lipid profile changes in the severely obese after laparoscopic sleeve gastrectomy (LSG), 1, 3, and 5 years after surgery. Obes Surg 25(2):285-289 
28. Blanco DG, Funes DR, Giambartolomei G et al (2019) High cardiovascular risk patients benefit more from bariatric surgery than low cardiovascular risk patients. Surg Endosc 33(5):1626-1631

29. Wei JH, Chou RH, Huang PH et al (2018) Metabolic surgery ameliorates cardiovascular risk in obese diabetic patients: influence of different surgical procedures. Surg Obes Relat Dis 14(12):1832-1840

30. Owan T, Avelar E, Morley K et al (2011) Favorable changes in cardiac geometry and function following gastric bypass surgery: 2-year follow-up in the Utah obesity study. J Am Coll Cardiol 57(6):732-739. https://doi.org/10. 1016/j.jacc.2010.10.017

31. Omran J, Firwana B, Koerber $S$ et al (2016) Effect of obesity and weight loss on ventricular repolarization: a systematic review and meta-analysis. Obes Rev 17(6):520-530. https://doi.org/10.1111/obr.12390

32. Mukerji R, Petruc M, Fresen JL et al (2012) Effect of weight loss after bariatric surgery on left ventricular mass and ventricular repolarization in normotensive morbidly obese patients. Am J Cardiol 110(3):415-419. https://doi.org/10.1016/j.amjcard.2012.03.045

33. Mauricio SC, Lisandro M, Carlos ER et al (2019) Bariatric surgery and rapid weight loss improve ventricular ejection fraction in severely obese subjects with heart failure. J Am Coll Surg 229:S17. https://doi.org/10.1016/j. jamcollsurg.2019.08.051

34. Aggarwal R, Harling L, Efthimiou E et al (2016) The effects of bariatric surgery on cardiac structure and function: a systematic review of cardiac imaging outcomes. Obes Surg 26(5):1030-1040

35. Tavares Ida S, Sousa AC, Menezes Filho RS et al (2012) Left ventricular diastolic function in morbidly obese patients in the preoperative for bariatric surgery. Arq Bras Cardiol 98:300-306

36. Valezi AC, Machado VH (2011) Morphofunctional evaluation of the heart of obese patients before and after bariatric surgery. Obes Surg 21:1693-1697

37. Wong C, Marwick TH (2007) Obesity cardiomyopathy: pathogenesis and pathophysiology. Nat Clin Pract Cardiovasc Med 4:436-443

\section{Publisher's Note}

Springer Nature remains neutral with regard to jurisdictional claims in published maps and institutional affiliations.

\section{Submit your manuscript to a SpringerOpen ${ }^{\circ}$ journal and benefit from:}

- Convenient online submission

- Rigorous peer review

- Open access: articles freely available online

- High visibility within the field

- Retaining the copyright to your article

Submit your next manuscript at $\boldsymbol{\nabla}$ springeropen.com 